\title{
Possibilidades de inclusão do Parque Estadual do Ibitipoca/MG na rede de geoparques $^{1}$
}

\section{Possibilities include the State Park of Ibitipoca/MG in the geoparks network}

\author{
Lilian Carla Moreira Bento \\ Professora Substituta da Universidade Federal de Uberlância \\ liliancmb@yahoo.com.br \\ Silvio Carlos Rodrigues \\ Prof. Dr. em Geografia Física - Universidade Federal de Uberlândia \\ silgel@ufu.com
}

Artigo recebido para revisão em 31/10/2014 e aceito para publicação em 05/12/2014

\begin{abstract}
Resumo:
Minas Gerais é um estado reconhecido pela sua rica e fascinante geodiversidade e muitas de suas unidades de conservação, mesmo que a justificativa maior para a sua criação tenha sido a biodiversidade, vem refletir esse cenário. O Parque Estadual do Ibitipoca é uma dessas unidades, inclusive é o parque estadual mais visitado no estado, sinalizando para a grande beleza cênica e importância ecológica do seu patrimônio natural. Esse parque apresenta uma geodiversidade bem heterogênea, com várias cavernas esculpidas em quartzito, quedas d'água, praias fluviais, pontes naturais, mirantes, entre outros que tanto fascinam aqueles que o visitam. Tendo em vista essas características e a necessidade de se dar mais visibilidade a temática do geopatrimônio, o objetivo do presente estudo é refletir sobre as possibilidades dessa unidade em integrar a Rede Global de Geoparques Nacionais (RGGN) da UNESCO. A metodologia empregada para atingir esse objetivo foi correlacionar todas as características do parque com o documento em que a UNESCO estabelece os critérios necessários para compor a RGGN.
\end{abstract}

Palavras-chave: Parque. Turismo. UNESCO.

\begin{abstract}
:
Minas Gerais is a state recognized by its rich and fascinating geodiversity and a lot of its conservation units, even if the bigger reason for its creation has been the geodiversity, such scenario is reflected. State Park of Ibitipoca is one of these units, even being the state park most visited in the state, pointing to the great scenic beauty and ecological importance of its natural patrimony. This park presents such a varied geodiversity, with several caves carved in quartzite, water falls, fluvial beaches, natural bridges, miradors, among others that so much fascinate those who visit it. Having in mind these characteristics and the necessity to give more visibility to the theme of geopatrimony to integrate the Global Net of National Geoparks (GGN) of UNESCO. The methodology used to reach such objective was to correlate all the park characteristics with the document in which UNESCO establishes the criteria necessary to be part of GGN.
\end{abstract}

Keywords: Park. Tourism. UNESCO.

${ }^{1}$ Compreende um dos capítulos da tese do autor principal. 


\section{INTRODUÇÃO}

$\mathrm{Na}$ atualidade muito esforço já foi realizado no sentido de valorização e divulgação do conceito de biodiversidade, em contrapartida, o conceito de geodiversidade ainda é desconhecido por muitas pessoas, o que o torna muito vulnerável a degradação. Um exemplo dessa discrepância é a criação de unidades de conservação que tem a geodiversidade negligenciada em prol da biodiversidade, apesar dessa compor cenários de grande beleza e ser "[...] o berço da vida, da renovação e das metamorfoses dos seres vivos" (SIMPÓSIO... 1991).

Visando reverter esse quadro, algumas iniciativas nacionais e internacionais têm sido criadas e a Rede Global de Geoparques da Unesco é um exemplo de iniciativa de âmbito global que tem conseguido atrair diversos países que já começam a mostrar uma preocupação com o seu geopatrimônio.

Entrar para essa rede depende de uma série de critérios que buscam normatizar e orientar os Estados-membros interessados e os geoparques devem ser concebidos como instrumentos voltados não apenas a proteção dos patrimônios (natural e cultural), como também de fortalecimento da identidade local e de desenvolvimento econômico sustentável, por meio do geoturismo, por exemplo.

O Parque Estadual do Ibitipoca (PEI) é uma unidade de conservação localizada num domínio geológico-geomorfológico em que a litologia associada ao relevo acidentado proporcionou um riquíssimo potencial turístico, o qual chama a atenção não só pela sua beleza cênica, mas por agrupar numa pequena área uma gama diversificada de geoformas de grande valor ecológico, cênico, turístico, educativo e científico, como cavernas, pontes naturais, quedas d'água, praias fluviais, mirantes etc. Características essas com grande potencial para a prática do geoturismo.

Diante desses aspectos naturais do parque e da necessidade de se efetuar estudos que deem visibilidade a temática do geopatrimônio, surgiram alguns questionamentos relacionados à possibilidade do PEI integrar a RGGN da UNESCO, entre eles: $i$ - a existência de geossítios é argumento suficiente para sua inserção? ii- apenas a área do parque basta? iii- esse parque está dotado de todos os requisitos necessários para compor um geoparque? $i v$ - quais suas potencialidades e limitações?

Sendo assim, a metodologia empregada nesse estudo foi revisão bibliográfica, a qual ficou estruturada em levantamento, localização e fichamento de obras pertinentes ao tema, principalmente de documentos obtidos no site da RGGN da UNESCO e de uma publicação especial da Revista Geologia da USP, na qual estão os artigos referentes às palestras proferidas e transcrição das mesasredondas do "Workshop GEOPARQUE - Estratégia de Geoconservação e Projetos Educacionais", 
que ocorreu em São Paulo no ano de 2009. Posteriormente foram correlacionados com dados obtidos em trabalhos de campo no Parque Estadual do Ibitipoca, os quais possibilitaram efetuar o inventário dos geossítios e sua posterior avaliação e quantificação. A partir dessa metodologia foi possível analisar o documento "Guidelines and Criteria for National Geoparks seeking UNESCO's assistance to join the Global Geoparks Network (GGN)", chegando aos resultados expostos a seguir neste artigo.

\section{RESULTADOS E DISCUSSÃO}

\subsection{Geoconservação: instrumento de conservação da geodiversidade?}

Muitas são as ameaças à geodiversidade, sendo o homem o seu principal agente modificador e destruidor. Essas ameaças afetam direta e/ou indiretamente a geodiversidade e são tanto maiores e mais graves devido a falta de um conjunto de regras, bem como ao desrespeito às mesmas.

Salvan (1994) citado por Nascimento; Ruchkys; Mantesso Neto (2008) argumenta que a causa principal da destruição da geodiversidade é justamente a falta de conhecimentos sobre sua existência e importância, o que está relacionado com a questão da ignorância cultural, tornando essa vertente abiótica da natureza mais vulnerável.

Na tentativa de modificar esse panorama de vulnerabilidade têm sido criadas estratégias visando à conservação da geodiversidade: a geoconservação, ramo da atividade científica que visa caracterizar, conservar e gerir o geopatrimônio e processos naturais associados (BRILHA, 2005).

O objetivo da geoconservação não é conservar toda a geodiversidade, mas o geopatrimônio, ou seja, porções dessa geodiversidade que tenham significativa relevância, de forma a manter a evolução natural dos aspectos geológicos e geomorfológicos.

Segundo Gronggrijip (2000) citado por Nascimento; Ruchkys; Mantesso Neto (2008) a geoconservação busca compatibilizar proteção e uso do geopatrimônio, uma vez que ele [...]:

\footnotetext{
- é um componente importante do Patrimônio Natural;

- representa uma importante herança cultural, de um caráter que não se repete;

- constitui uma base imprescindível para a formação de cientistas e profissionais;

- constitui um elemento de proteção de recursos estéticos e recreativos;

- serve para estabelecer uma ligação entre a história da Terra e a história dos homens e sua evolução biológica (GALLEGO; GARCIA, 1996 apud MOREIRA, 2008, p. 76-77).
}

Brilha (2005) considera que, para proceder a geoconservação, é necessário estabelecer um ordenamento metodológico bem criterioso, estruturado em diversas etapas, as quais devem estar amparadas por uma legislação ambiental que permita a proteção desse tipo de patrimônio. Por meio desse ordenamento é colocado que a geoconservação não pretende conservar toda a geodiversidade, 
apenas a parte dela que tenha valor destacado (ecológico, turístico, didático, científico...), o qual é obtido através das etapas iniciais de inventariação e quantificação. E, tendo em vista a avaliação da vulnerabilidade destas áreas, existe a possibilidade do geossítio ser submetido a estratégias de conservação ou de valorização e divulgação, todos devendo ser monitorados ao longo do tempo.

\subsection{O papel dos geoparques na geoconservação}

Nas últimas décadas aconteceram ações voltadas à geoconservação, algumas num contexto internacional e outras nacionais, o foco deste trabalho será a Rede Global de Geoparques Nacionais da UNESCO. Esse programa foi inicialmente discutido em 1996, vndo a ser implantado apenas em 2004, em reunião realizada na sede da UNESCO, em Paris, com o objetivo de identificar áreas naturais com elevado valor geológico, passíveis de implementação de estratégias de conservação e a difusão de conhecimentos, permitindo o desenvolvimento sustentável para toda a região abrangida (ARAÚJO, 2005; RUCHKYS, 2007; LIMA, 2008; MOREIRA, 2008; NASCIMENTO, 2014).

Um geoparque deve ter uma

[...] area with clearly defined boundaries and a large enough area for it to serve local economic and cultural development (particularly through tourism). Each Geopark should display though a range of sites of international, regional and/or national importance, a region's geological history, and the events and processes that formed it. The sites may be important from the point of view of science, rarity, education and/or aesthetics (UNESCO, 2010, p.3).

Guy Martini ${ }^{2}$, da RGGN da UNESCO, esclarece que, ao contrário do que se pensa, o prefixo geo da palavra Geoparque não se refere apenas a vertente geológica, mas a Terra, esses locais devendo ser encarados, portanto, como "espaços que integram passado, presente e futuro, destacando não só a geologia, mas os homens e a sua cultura”.

Boggiani $^{3}$ também argumenta que o papel dos geoparques não é apenas o da geoconservação, mas o de se transformarem em projetos de desenvolvimento para as populações locais, trazendo-as para dentro do geoparque e não as excluindo. Brilha ${ }^{4}$ acrescenta que os geoparques são áreas que conjugam geoconservação e desenvolvimento econômico sustentável das populações que a habitam, envolvendo, respectivamente, patrimônio geológico, biodiversidade, patrimônio cultural e comunidade; ciência, educação, geoturismo e sustentabilidade.

\footnotetext{
${ }^{2}$ Trecho da palestra de Guy Martini apresentada no Workshop Geoparque: estratégia de geoconservação e projetos educacionais, em São Paulo, SP, julho, 2009.

${ }^{3}$ Trecho da palestra de Paulo César Boggiani apresentada no Workshop Geoparque: estratégia de geoconservação e projetos educacionais, em São Paulo, SP, julho, 2009.

${ }^{4}$ Trecho da palestra de José Brilha apresentada no Workshop Geoparque: estratégia de geoconservação e projetos educacionais, em São Paulo, SP, julho, 2009.
} 
Os geoparques são áreas bem delimitadas e que possuem rico geopatrimônio, entretanto, mais do que isso, são locais que precisam se apresentar como fonte de renda para a população local que deve ser incluída nesse projeto que vai além da geoconservação, abarcando princípios mais amplos que é o do desenvolvimento sustentável local e o da geoeducação (BACCI et al., 2009; BRILHA, 2009; MODICA, 2009).

Segundo a UNESCO (2010), as principais atribuições de um geoparque são:

- - Preservar o geopatrimônio para as gerações presentes e futuras.

- - Educar o público em geral sobre os problemas em ciências geológicas e sua relação com as questões ambientais.

- - Garantir o desenvolvimento econômico sustentável.

- - Promover pontes multiculturais com o patrimônio, conservação e manutenção da diversidade geológica e cultural, utilizando sistemas de parceria.

- - Estimular a pesquisa.

- - Contribuir ativamente para a vida da rede através de iniciativas conjuntas de colaboração e divulgação.

- - Colaborar com artigos para os boletins RGGN, livros e demais tipos de publicações.

Em síntese, pode-se dizer que os objetivos primários de um geoparque baseiam-se no tripé: conservação, educação e desenvolvimento regional, sendo o geoturismo um importante instrumento nesse intento. Bento e Rodrigues (2014) explicam que isso ocorre, pois ele soma à contemplação dos geossítios o seu entendimento, gerando um viés educativo que possibilita a valorização da geodiversidade e um sentimento de respeito e responsabilidade pela manutenção da conservação ambiental. Além disso, sua prática, aliada aos demais segmentos turísticos, permite a ampliação do tempo de permanência dos turistas, gerando mais lucros para o centro receptor.

Até o momento existem cerca de 111 geoparques distribuídos em 32 Estados-membros e 5 continentes (Mapa 1). Deste total, um está localizado no Brasil: o Geopark Araripe, o primeiro criado na América do Sul. Localizado no Estado do Ceará possui cerca de $5.000 \mathrm{~km}^{2}$ e é resultado da iniciativa do Governo do Estado do Ceará e coordenação pela Universidade Regional do Cariri URCA.

Importante frisar que em 2006 a CPRM criou o Projeto Geoparques, visando "identificar, classificar, descrever, catalogar, georreferenciar e divulgar os parques geológicos do Brasil, além de definir diretrizes para o seu desenvolvimento sustentável", com o papel de, segundo Schobbenhaus e Silva (2012), indutor na criação de geoparques brasileiros. 
Mapa 1: Distribuição dos geoparques na GGN

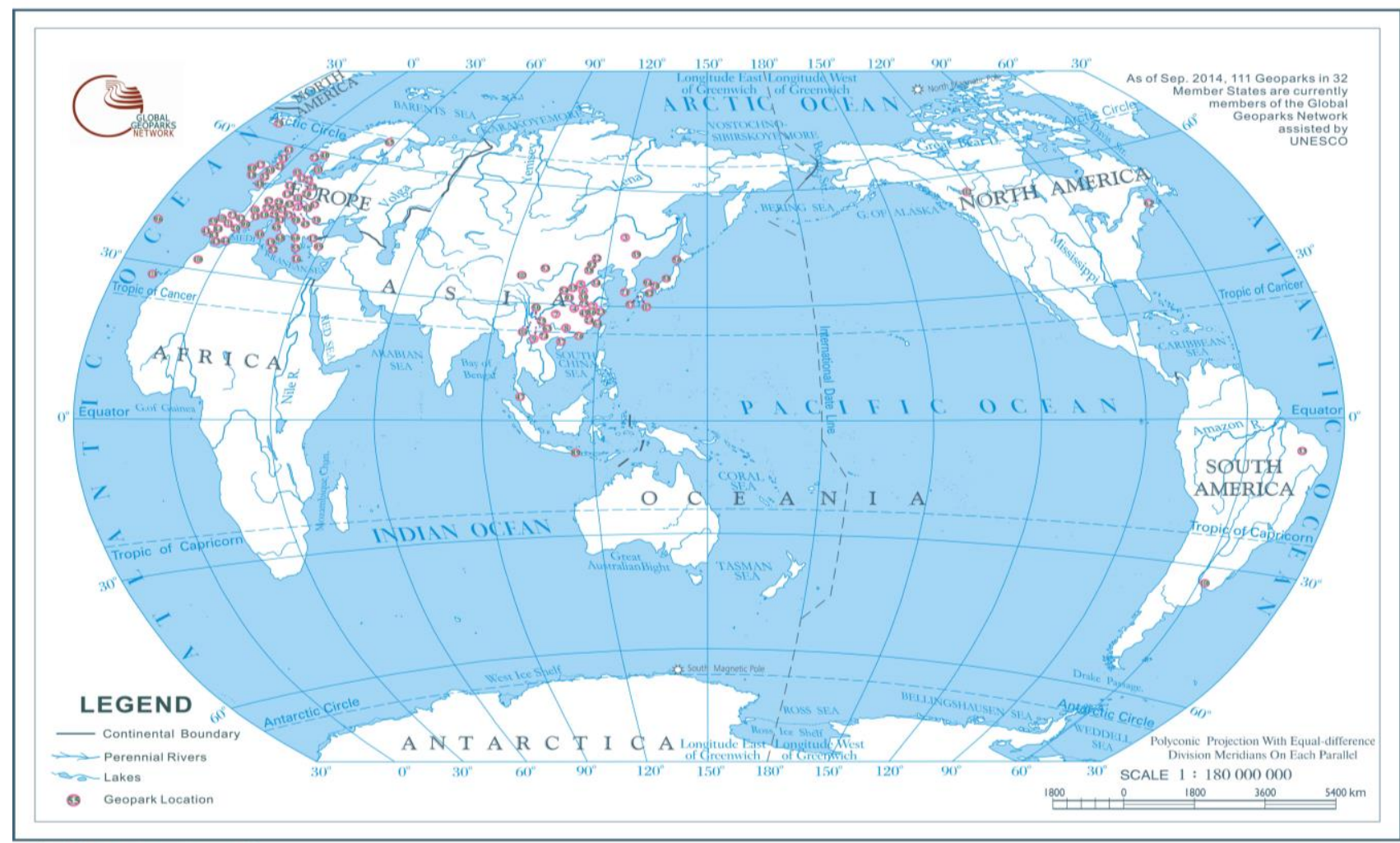

审图号: GS (2008) 1895 号

Fonte:

http://www.globalgeopark.org/UploadFiles/2012_5_7/GGN\%20Map2014/GGN\%20Distribution\%202014.12.3\%20$\% 20$ no\%20national\%20boundary3600.jpg

\subsection{Potencialidades e limitações do Parque Estadual do Ibitipoca para integrar um geoparque}

Neste item serão trabalhadas as potencialidades e limitações do PEI para integrar um geoparque, a partir da análise do documento "Guidelines and Criteria for National Geoparks seeking UNESCO's assistance to join the Global Geoparks Network (GGN)", no qual a UNESCO estabelece algumas orientações e critérios para quem busca participar da RGGN:

1- Tamanho e configuração: Entre as orientações estabelecidas destacam-se três aspectos principais, a saber: $i$ ) a área do geoparque deve ter um limite claramente definido, $i i$ ) deve ser grande o suficiente para que sirva ao desenvolvimento econômico e cultural local (ênfase na atividade turística) e iii) deve levar em conta toda a configuração da região e não apenas locais de importância geológica.

O Parque Estadual do Ibitipoca é uma Unidade de Conservação criada em 1973, tendo como municípios limítrofes Lima Duarte, Bias Forte e Santa Rita do Ibitipoca. Compreende uma área total de 1.488 hectares e é, de acordo com dados do IEF (2012), o parque estadual mais visitado em 
Minas Gerais, gerando emprego e renda para a região, aqui entendida como os residentes dos municípios limítrofes ao parque, como Lima Duarte, Bias Forte e Santa Rita do Ibitipoca.

Considerando esse critério, o parque tem poucas chances de compor um geoparque, pois é uma área pequena e, sendo uma unidade de conservação de uso integral, são poucas as atividades econômicas que podem ser desenvolvidas no seu interior. Em contrapartida, ele está inserido no Circuito Turístico Serras de Ibitipoca, o qual é composto por nove municípios: Bias Forte, Bom Jardim de Minas, Ibertioga, Lima Duarte, Pedro Teixeira, Rio Preto, Santa Rita de Ibitipoca, Santa Rita de Jacutinga e Santana do Garambéu, totalizando uma área de 3.478 km² (Mapa 2).

Esses municípios apresentam afinidades que justificaram a criação desse circuito, no caso, as serras: Ibitipoca (que deu origem ao nome do circuito), Lima Duarte, Negra, da Cruz, da Boa Vista e da Cachoeira Alegre, compartilhando de uma mesma história geológica, principalmente dos eventos relacionados ao Proterozóico. Além disso, têm uma história estreitamente relacionada com a mineração, uma vez que compreendem antigos caminhos de tropeiros e garimpos, pontos de registro de impostos do ouro, bem como ainda povoados Quilombolas.

Mapa 2: Municípios pertencentes ao Circuito Serras de Ibitipoca

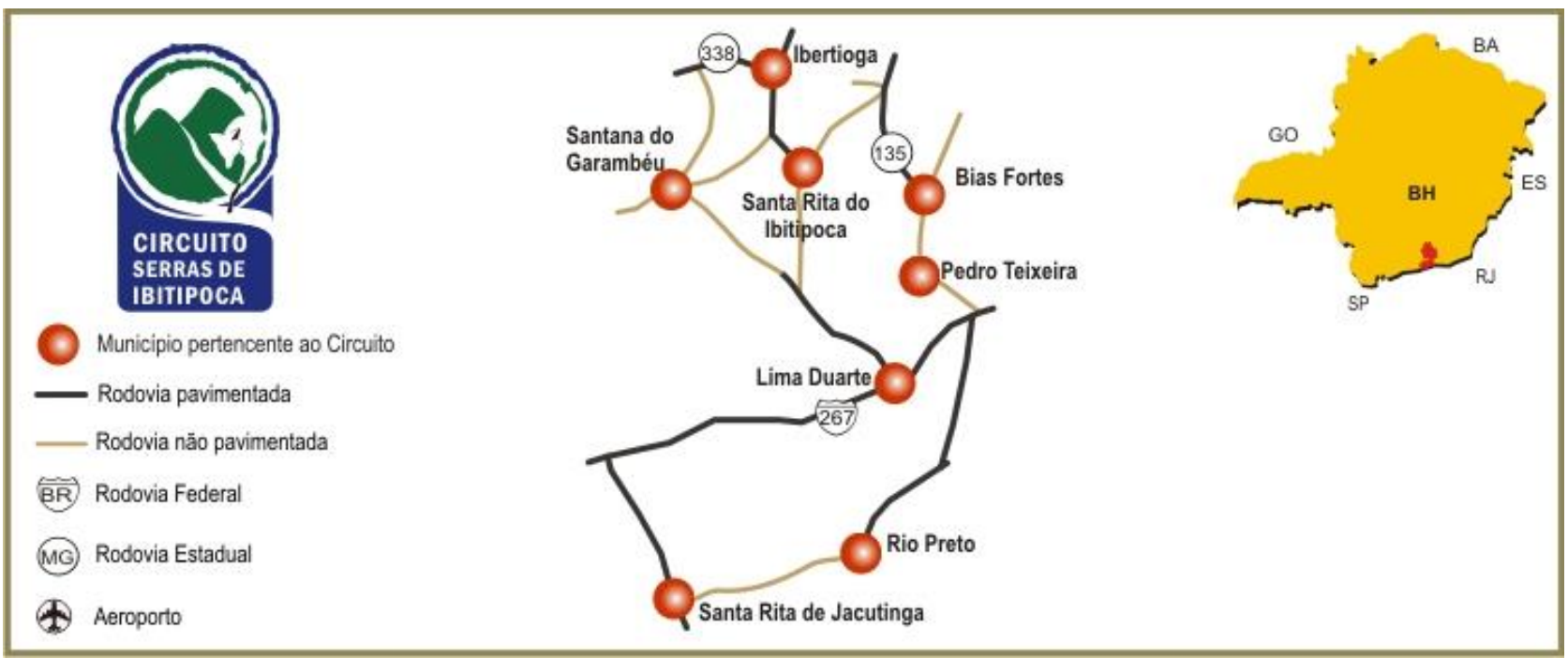

Fonte: http://www.turismo.mg.gov.br/circuitos-turisticos/lista-de-circuitos/987-circuito-turistico-serras-do-ibitipoca-.

Esse circuito é abundante não apenas de atrativos de base natural, relacionados à bio e geodiversidade (Figura 1), como também de atrativos de cunho cultural (material e imaterial), como construções (igrejas e fazendas) no estilo barroco, festividades como a do Carro de Boi, sendo que Ibertioga é tida como a capital nacional dos carros de boi, isso sem falar no aspecto gastronômico (circuito reconhecido pela qualidade da cachaça, doces diversos e o famoso pão-de-canela) e dos produtos artesanais feitos de palha de milho, bonecas de cabaça, peças em barro e bambu, entre outros. 
Figura 1: Mosaico com alguns dos atrativos do PEI: (A): Ponte de Pedra, (B): Prainha, (C): Cachoeira dos Macacos, (D): Janela do Céu, (E): Gruta dos Três Arcos e (F): Pico do Pião
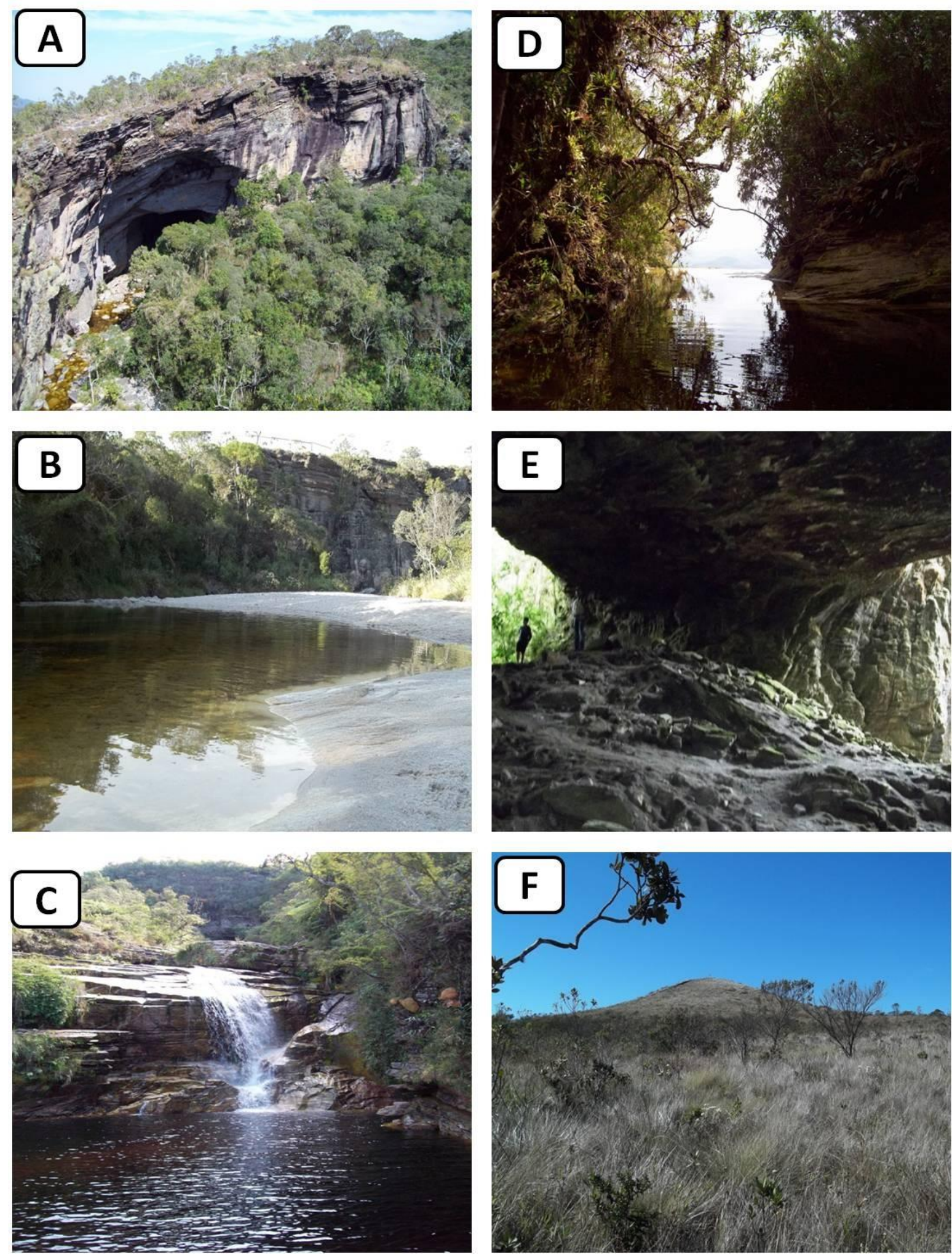

Fonte: $\mathrm{O}$ autor. 
Outro aspecto interessante é a existência de geossítios com valor cultural. No PEI existem diversos locais onde é possível associar o geopatrimônio com a questão cultural, como no Cruzeiro, local panorâmico onde todo dia 3 de maio o terço cantado com a participação da comunidade local; a Gruta dos Fugitivos onde foram encontradas em 1912 ruínas de um antigo refúgio de escravos; o Pico do Pião, local onde estão as ruínas da antiga capela Senhor Bom Jesus da Serra e o Lago das Miragens que, segundo uma lenda local, há muito tempo dois guerreiros indígenas lutaram pelo amor de uma jovem mulher, o preferido da jovem morreu e ela se suicidou nesse lago, onde podem ser vistos de mãos dadas, no fundo. Já em outros municípios do circuito, como em Rio Preto foi construída uma capela dentro da Gruta do Funil; em Santana do Garambéu existe uma igreja toda construída com pedras e numa gruta de Santa Rita do Ibitipoca há um local onde dizem que a água é santa.

Enfim, considerando esse primeiro critério, é inviável a inclusão do PEI, a não ser que seja considerado no contexto de todo o circuito turístico a qual ele já faz parte. Isso porque de acordo com a SETUR (2002), as principais características dos circuitos também são os aspectos geográficos (a região limitada deve apresentar atributos culturais, físicas e sociais que criam uma sensação de identidade cultural) e aspectos multitemáticos (os municípios oferecem uma diversidade enorme de atrativos: rural, ecológico, saúde, eventos, religioso, cultural, gastronomia etc.).

2- Gestão local e participação: nesse critério é dado destaque a importância do envolvimento e participação da comunidade local (dos municípios limítrofes ao parque), bem como de autoridades públicas, interesse privado, pesquisadores e entidades de ensino. É citada também a necessidade de criação de um sistema eficaz de gestão.

Por ser uma unidade de conservação integral é complicado pensar em gestão local e participação; entretanto, no contexto dos circuitos é mais fácil, até mesmo porque eles já supõem certa organização social, com o apoio local da comunidade, poder público e privado. A SETUR (2002) explica que os circuitos são administrados por entidades sem fins lucrativos e regidos por um estatuto, com a participação de membros da sociedade civil, do poder público e de empresas da Cadeia Produtiva do Turismo.

Sendo assim, é possível adaptar esse sistema de organização social dos circuitos, aproveitando sua experiência no que diz respeito, principalmente, ao envolvimento da comunidade local, uma vez que é uma das premissas dos geoparques para o desenvolvimento sustentável.

A partir desse critério é importante pensar a comunidade local como uma aliada em todo o processo de criação e manutenção do geoparque, não só usufruindo das benesses advindas do 
desenvolvimento econômico, mas compreendo a importância dessa área e ajudando na sua conservação, sendo co-responsáveis.

3- Desenvolvimento econômico: é preciso estimular a atividade econômica no âmbito do desenvolvimento sustentável, a partir, por exemplo, da criação de empresas locais inovadoras, pequenos negócios, indústrias caseiras, entre outros, gerando novas fontes de receita através do turismo, principalmente, do geoturismo.

Para entender esse critério é preciso remontar ao conceito de desenvolvimento sustentável, termo que aparece pela primeira em 1983, quando a Comissão Mundial sobre Meio Ambiente e Desenvolvimento (CMMAD) apresentou o relatório intitulado "Nosso futuro comum" ou "Relatório Brundtland":

[...] desenvolvimento sustentável é a atividade que harmoniza o imperativo do crescimento econômico com a promoção da equidade social e a preservação do patrimônio natural, garantindo assim que as necessidades das atuais gerações sejam atendidas sem comprometer o atendimento das necessidades das gerações futuras (RELATÓRIO BRUNDTLAND, 1984 apud BRASIL, 2008, p. 18).

Apesar de muito criticado, esse conceito vem ressaltar as inter-relações entre as diferentes variáveis do desenvolvimento (econômico, social, político e ambiental), mostrando a necessidade de um planejamento que leve em considerações todas elas, para o bem das gerações futuras e vindouras. Pensando nisso, a RGGN encara os geoparques como locais onde é possível estabelecer interfaces entre essas variáveis, tendo como principal atividade econômica o turismo.

Para atingir esse critério, mais uma vez, é preciso extrapolar os "muros" do PEI e pensar no ambiente do Circuito Serras de Ibitipoca, onde o turismo já é uma das principais atividades econômicas. Além disso, a configuração dos circuitos tende a esse tipo de desenvolvimento, uma vez que busca repartir os benefícios da atividade entre os municípios participantes. Isso é possível dada sua configuração, pois são constituídos por centros turísticos, ou seja, municípios com uma infraestrutura para receber os turistas e unidades turísticas, localidades menores e desprovidas de infraestrutura para abrigar os turistas, mas com atrativos naturais e culturais que podem ser desfrutados ao longo do dia. Essas unidades contribuem, ainda, suprindo esses centros com serviços e produtos que serão consumidos pelos turistas, como frutas, hortaliça, laticínios, artesanatos, entre outros, ressaltando, portanto, o caráter de "complementaridade" que existe entre os centros e as unidades turísticas dos circuitos (SANTOS, 2004).

E outro aspecto a se considerar é que o turismo é uma atividade econômica com caráter multiplicador. Isso significa que envolve não apenas serviços e produtos diretamente relacionados 
com o turismo, mas também indiretamente, dinamizando toda a economia local, possibilitando a sustentabilidade econômica do circuito.

Tendo em vista que o diferencial maior dos geoparques é o seu geopatrimônio, o geoturismo é a prática mais adequada a ser realizada nesses locais. Todavia, considerando as demais características inerentes aos geoparques, é essencial que o geoturismo seja trabalho em interface a diferentes segmentos turísticos, valorizando e divulgando os patrimônios natural e cultural de forma integrada e sistêmica.

Outro aspecto a se considerar é que o turismo gera impactos (positivos e negativos), os quais devem ser previstos mediante um rigoroso processo de planejamento, premissa indispensável para que a atividade seja de fato considerada sustentável, isto é, como "[...] a atividade que satisfaz as necessidades dos turistas e as necessidades socioeconômicas das regiões receptoras, enquanto a integridade cultural, a integridade dos ambientes naturais e a diversidade biológica são mantidas para o futuro" (OMT, 1999 apud BRASIL, 2008, p. 25).

4- Educação: cabe ao geoparque fornecer e organizar suportes, instrumentos e atividades de comunicação do conhecimento geocientífico (museus, centros interpretativos, trilhas, visitas guiadas etc.) para o público e comunidades locais.

Os geoparques devem ser grandes ferramentas educacionais, atuando não só no seu interior, mas junto a instituições locais, como nas escolas. No Geoparque Naturtejo, em Portugal, por exemplo, eles têm dois programas educativos: "A escola vai ao geopark" e "O geopark vai a escola", sinalizando a necessidade dessa interação geoparque-comunidade, sendo voltados exclusivamente para o público estudante (SCHOBBENHAUS FILHO, 2010).

Mas os geoparques devem atuar também junto aos visitantes e, para isso, são importantes os programas interpretativos. Woodley-Stewart e Pickett (2009, p. 60) argumentam que a "interpreting the natural world is one of the most important aspects of the working life of a Geopark [...] and how great interpretation can leave lasting memories for people”.

Diante da importância da interpretação ambiental, independentemente da forma como ela venha a ocorrer (meios personalizados ou não personalizados), é preciso que seja atrativa, criativa e persuasiva para que consiga levar o conhecimento das Geociências para o público em geral, contribuindo para a valorização e divulgação do geopatrimônio.

Sendo uma unidade de conservação integral, o PEI deve possuir programas educativos, voltados à sensibilização dos visitantes. Entretanto, conforme consta no plano de manejo, não existe um programa de educação e interpretação ambiental que possa promover o uso sustentável dos 
recursos naturais (IEF, 2007), esta sendo uma das grandes demandas do parque e do Circuito Serras do Ibitipoca que também não tem nenhum tipo de projeto que se enquadre nesse critério.

5- Proteção e conservação: um geoparque não é uma nova categoria de unidade de conservação e sua conservação deve acontecer em consonância com as tradições locais e legislação ambiental nacional, contribuindo para a conservação de importantes características geológicas.

No Brasil ainda não há uma legislação específica que classifique e proteja os geossítios, mas existe a Lei $\mathrm{n}^{\circ} 9.985$ de 18 de julho de 2000 que instituiu o Sistema Nacional de Unidades de Conservação, na qual a proteção do geopatrimônio se dá de forma indireta, sendo que algumas unidades têm um potencial maior para a proteção desse tipo de patrimônio, a saber: a) Unidade de proteção direta: Parques e Monumentos Naturais e b) Unidades de uso indireto: Área de proteção ambiental e Reserva Particular do Patrimônio Natural.

Um dos objetivos destas unidades, que podem ser de uso indireto/integral (se permite apenas atividades ligadas à pesquisa científica, educação ambiental e ao turismo) ou de uso direto/sustentável (é permitida outras atividades que sejam sustentáveis), relacionadas ao geopatrimônio, é "[...] proteger as características relevantes de natureza geológica, geomorfológica, espeleológica, arqueológica, paleontológica e cultural" (SNUC, $7^{\circ}$ objetivo) ou "proteger e recuperar recursos hídricos e edáficos" (SNUC, $8^{\circ}$ objetivo).

No caso do PEI, apesar do seu rico geopatrimônio, a justificativa para sua criação foi, principalmente, em função da sua biodiversidade, uma vez que engloba formações vegetais que integram o Bioma Mata Atlântica, numa área prioritária para a conservação da flora do Estado de Minas Gerais. Apesar disso, por ser uma unidade de conservação, pressupõe-se a proteção de todo o seu patrimônio natural, com medidas de proteção e monitoramento ambiental.

Quanto aos municípios do circuito Serras do Ibitipoca, existe a possibilidade de criação de uma Reserva Particular do Patrimônio Natural - RPPN. Ao criar esse tipo de unidade de conservação particular se garante não apenas a proteção ambiental, mas alguns benefícios para o proprietário da terra, entre eles: direito de propriedade preservado; isenção de Imposto Territorial Rural - ITR, referente à área reconhecida como RPPN; prioridade de análise dos projetos pelo Fundo Nacional de Meio Ambiente - FNMA; preferência na análise de pedidos de crédito agrícola junto a instituições de crédito em propriedades que contiverem RPPN em seus perímetros; maiores possibilidades de apoio dos órgãos governamentais para fiscalização e proteção da área, por ser uma Unidade de Conservação; possibilidade de cooperação com entidades privadas e públicas na proteção, gestão e manejo da RPPN etc. (IEF, [200?]). 


\section{ALGUMAS CONSIDERAÇÕES E RECOMENDAÇÕES}

No intuito de reverter o quadro de destruição e descaso para com a geodiversidade vem ocorrendo diferentes iniciativas como realização de eventos, publicações, projetos científicos e programas de âmbito nacional e internacional, como a RGGN da UNESCO. A criação dessa rede é um grande avanço na luta pela valorização do geopatrimônio, ao mesmo tempo em que mostra a possibilidade de criação de um território voltado não só a proteção da natureza, mas que busca colocar em prática as premissas do desenvolvimento sustentável, aliando conservação ambiental com o desenvolvimento econômico e social.

Apesar da grande riqueza do seu geopatrimônio, no Brasil existe apenas um geoparque nos moldes da RGGN, o que inevitavelmente tem movido muitas pesquisas voltadas a inventariação e seleção de áreas com potencial para compor um geoparque, tal como essa pesquisa se propôs em fazer.

A partir da metodologia empregada se infere que o PEI possui muitos aspectos relevantes na configuração de um geoparque, principalmente no que diz respeito ao seu potencial geoturístico. Inclusive, em pesquisa anterior, Bento e Rodrigues (2014) constataram que esse parque possui os três pilares básicos para a prática do geoturismo: geoatrativos, infraestrutura e turistas. Todavia, apenas ter potencial geoturístico não basta, pois os geoparques devem combinar outros aspectos como desenvolvimento econômico local e ter um viés educativo muito bem trabalhado, tanto na esfera formal como informal, o que suscita a necessidade, respectivamente, de uma área geográfica maior e investimentos em interpretação ambiental, com criação de roteiros geoturísticos (devem ser integrados aos demais tipos de patrimônio, oportunizando o entendimento do meio ambiente no geral), painéis interpretativos, folders, capacitação dos guias e monitores, entre outros.

Tento em vista a limitação territorial é recomendável inserir o PEI numa área maior, tal como já está inserido no Circuito Serras de Ibitipoca, aproveitando os municípios pertencentes, uma vez que contam com uma identidade local e certa organização social e, além disso, sendo uma unidade de conservação de uso integral não há residentes locais que se beneficiariam diretamente. $\mathrm{O}$ primeiro passo nesse sentido é recorrer às etapas da geoconservação propostas por Brilha (2005), inventariando e quantificando os geossítios desses municípios, para selecionar os que serão alvos de programas de conservação e aqueles que têm condições de serem comercializados, passando por estratégias de valorização e divulgação.

Diante do que foi exposto se conclui, portanto, que o PEI apresenta potencialidades e limitações para sua inclusão na RGGN e que suas chances serão aumentadas se for incluído no contexto do Circuito Serras de Ibitipoca. Mas, ainda assim, existe um longo caminho a ser trilhado, com muitas pesquisas a serem realizadas (principalmente relacionadas à avaliação de geossítios), 
parcerias a serem firmadas entre o poder público, iniciativa privada e instituições de pesquisa, oficinas para sensibilizar, envolver e capacitar a comunidade local, bem como grandes investimentos na área da interpretação ambiental, para que os pressupostos educativos dos geoparques possam ser alcançados.

Espera-se, a partir desse estudo, ter lançado alguns esclarecimentos sobre essa temática e que os gestores do Parque Estadual do Ibitipoca e do Circuito Serras de Ibitipoca se sintam motivados a tentar essa inclusão, podendo usufruir dos seus benefícios, entre eles, poder compartilhar experiências com outros países que já fazem parte da RGGN, intercambiando metodologias e tecnologias, bem como recebendo reconhecimento internacional e dando maior visibilidade ao geopatrimônio do Brasil.

\section{AGRADECIMENTOS}

Agradecimentos à Coordenação de Aperfeiçoamento de Pessoal de Nível Superior (CAPES) pela bolsa de doutorado e ao Instituto Estadual de Florestas (IEF) pelo apoio à pesquisa.

\section{REFERÊNCIAS}

ARAÚJO, E. L. da S. Geoturismo: conceptualização, implementação e exemplo de aplicação ao Vale do Rio Douro no Setor Porto-Pinhão. 2005. 219 f. Dissertação (Mestrado em Ciências do Ambiente) - Escola de Ciências, Universidade do Minho, Minho, 2005.

BACCI, D. de L. C. et al. GEOPARQUE- Estratégia de conservação e projetos educacionais. Geologia, São Paulo, 2009, p. 07-15, publicação especial.

BENTO, L. C. M.; RODRIGUES, S. C. Geoturismo no Parque Estadual do Ibitipoca/MG: potencialidades e limitações. Boletim de Geografia, Maringá, v. 32, n. 2, 2014, p. 50-64, jan./abr. 2014.

BRASIL. Lei no 9.985, de 18 de julho de 2000. Instituiu o Sistema Nacional de Unidades de Conservação e dá outras providências. Cadernos da Reserva da Biosfera, São Paulo, 2 ed., n. 18, 2000. 76 p.

BRASIL Legislação ambiental básica. Brasília: Ministério do Meio Ambiente, UNESCO, 2008. $350 \mathrm{p}$.

BRILHA, J. Patrimônio geológico e geoconservação - a conservação da natureza na sua vertente geológica. Braga: Palimage, 2005. 190 p.

BRILHA, J. A importância dos geoparques no ensino e divulgação das Geociências. Geologia, São Paulo, 2009, p. 27-33, publicação especial. 
CIRCUITO SERRAS DE IBITIPOCA. Site oficial. Disponível em: <

http://www.turismo.mg.gov.br/circuitos-turisticos/lista-de-circuitos/987-circuito-turistico-serras-doibitipoca->. Acesso em: 11 jun. 2013.

CPRM. Projeto Geoparques. 8 p. Disponível em: 〈http://www.cprm.gov.br〉. Acesso em: mai. 2009.

IEF. Plano de manejo do Parque Estadual do Ibitipoca. Belo Horizonte: IEF, 2007. 130 p.

IEF. Visitação nas unidades de conservação estadual no período de 2006-2011 [mensagem pessoal]. Mensagem recebida por<liliancmb@yahoo.com.br>em 30 ago. 2012.

IEF. Texto sobre RPPN. Disponível em: <http:// http://www.ief.mg.gov.br/areasprotegidas/criacao-de-rppn>. Acesso em: 05 mai. 2013.

LIMA, F. F. de. Proposta metodológica para a inventariação do Patrimônio Geológico Brasileiro. 2008. 103 f. Dissertação (Mestrado em Patrimônio Geológico e Geoconservação) Escola de Ciências, Universidade do Minho, Minho, 2008.

MODICA, R. As redes europeia e global dos geoparques (EGN e GGN): Proteção do patrimônio geológico, oportunidade de desenvolvimento local e colaboração entre territórios. Geologia, São Paulo, 2009, p. 17-25, publicação especial.

MOREIRA, J. C. Patrimônio geológico em Unidades de Conservação: atividades interpretativas, educativas e geoturísticas. 2008. 428 f. Tese (Doutorado em Geografia) - Centro de Filosofia e Ciências Humanas, Universidade Federal de Santa Catarina, Santa Catarina, 2008.

NASCIMENTO, M. A. L. Você sabe o que é um geoparque? Revista Conhecimento Prático Geografia, Edição 55, Junho, 2014.

NASCIMENTO, M. A. L. ; RUCHYS, U. A. de; MANTESSO NETO, V. Geodiversidade, geoconservação e geoturismo - trinômio importante para a proteção do patrimônio geológico. São Paulo: Sociedade Brasileira de Geologia, 2008. 84 p.

RUCHKYS, U. A. de. Patrimônio geológico e geoconservação do Quadrilátero Ferrífero, Minas Gerais. 2007. 233 f. Tese (Doutorado em Geociências) - Instituto de Geociências, Universidade Federal de Belo Horizonte, Belo Horizonte, 2007.

SANTOS, A. A. A importância do circuito turístico para o fomento da economia e da preservação ambiental - caso São Roque de Minas. 2004. 113 f. Dissertação (Mestrado em Administração) - Programa de Pós-Graduação em Administração, Universidade Federal de Lavras, Lavras, 2004.

SETUR - Secretaria de Estado do Turismo. Relatório de atividades 1999/2002. Belo Horizonte: [s.n.], 2002.

SIMPÓSIO INTERNACIONAL SOBRE A PROTEÇÃO DO PATRIMÔNIO GEOLÓGICO,1., 1991, Digne-Les-Bains, França. Declaração Internacional dos Direitos a Memória da Terra. Tradução de Carlos Fernando de Moura Delphim. Disponível em: http://vsites.unb.br. Acesso em: 5 out. 2010. 
SCHOBBENHAUS, C.; SILVA, C. R. da (Orgs.). Geoparques do Brasil - propostas. Rio de Janeiro: CPRM, 2012. 748 p.

SCHOBBENHAUS FILHO, C. Relatório de viagem a Portugal - Geoparques Arouca e Naturtejo. Rio de Janeiro: CPRM, 2010. 47 p.

UNESCO. Guidelines and Criteria for National Geoparks seeking UNESCO's assistance to join the Global Geoparks Network (GGN). Paris: UNESCO, 2010. 12 p. Disponível em:

<http://www.globalgeopark.org/UploadFiles/2012_9_6/GGN2010.pdf>. Acesso em: 20 out. 2012.

UNESCO. Global Network of National Geoparks. Disponível em:

<http://www.globalgeopark.org>. Acesso em: 20 out. 2012.

WOODLEY-STEWART, C.; PICKETT, E. Interpretation in the Nort Pennines - "The memory making business". In: CARVALHO, C. N. de; RODRIGUES, J. (Eds.). New ChalleNges with geotourism - Proceedings of the VIII European Geoparks Conference. Portugal: Idanha-a-Nova, 2009. p. 45-50. 